Title: Endovascular treatment of dissecting aneurysms of the posterior inferior cerebellar artery and predictors of outcome

\author{
Hui $\mathrm{Li}^{1}, \mathrm{Xi-Feng} \mathrm{Li}{ }^{1}, \mathrm{Xu}$-Ying $\mathrm{He}^{1}, \mathrm{Xin}_{\mathrm{Zhang}}{ }^{1}, \quad$ Guo-hui Zhu ${ }^{1}$ \\ Qin-rui Fang ${ }^{1}$, Ze- qun Wang ${ }^{1}$, Chuan-Zhi Duan ${ }^{1} *$
}

Running head: Outcomes and prognostic factors of intracranial posterior inferior cerebellar artery of dissecting aneurysms

${ }^{1}$ Department of Neurosurgery/Neurosurgery Institute/Key Laboratory on Brain Function Repair and Regeneration of Guangdong, Southern Medical University, Zhujiang Hospital, 253\# industry road, 510282, Guangzhou, Guangdong, China;

*Corresponding Author: Director and Professor Chuan-Zhi Duan:

Address: Department of Neurosurgery/Neurosurgery Institute/Key Laboratory on Brain Function Repair and Regeneration of Guangdong, Southern Medical University, Zhujiang Hospital, 253\# industry road, 510282, Guangzhou, Guangdong, China;

Tel: +86-013539962233; Fax: +86-020-61643269;

E-mail: address: doctorduanzj@163.com.

Author: Hui $\quad$ Li $\quad$ Tel: +86-015625067898; Fax: +86-020-61643269;

E-mail:lihuiyt@126.com

Co-authors:

Xin Zhang: $\quad$ Tel: +86-015989058895; Fax: +86-020-61643269;

E-mail: zhangxinzjyy@163.com

Xu-Ying He: $\quad$ Tel: +86-013688877133; Fax: +86-020-61643269;

E-mail: hexuyingzj@163.com

Xi-Feng Li: $\quad$ Tel: +86-015915756355; Fax: +86-020-61643269; 


\title{
E-mail: lixifengzj@126.com
}

Guo-hui Zhu: Tel:+86-15360605664

E-mail: zhuguohuizj@163.com

Qin-rui Fang: Tel: +86-013570533615

E-mail: 815159425@qq.com

Ze- qun Wang: Tel: +86-013268269141

E-mail: 233277658@qq.com

\section{Acknowledgments: None.}

Disclosure: The authors have no personal financial or institutional interest in any of the drugs, materials, devices described in this article.

Funding: This work was supported by the National Science Foundation of China (grant number (81271315)

\begin{abstract}
Goals: Isolated dissecting aneurysms of the posterior inferior cerebellar artery are rare lesions which carry high risk of rebleeding and mortality. However, the existing literature concerning predictors of outcome after endovascular treatment is limited and controversial. Our present study retrospectively reviewed and analyzed the clinical outcome of endovascular treatment ruptured PICA dissecting aneurysms and explored the predictors of outcome.
\end{abstract}

Materials and methods: We retrospectively reviewed 17 consecutive patients with ruptured posterior inferior cerebellar artery dissecting aneurysms that underwent endovascular treatment from January 2003 to January 2014. 9 patients underwent selective coiling while 7 patients underwent parent artery occlusion; one patient underwent stent-assisted coiling. Follow-up outcomes were evaluated using modified 
Rankin Scale. The clinical outcomes of patients were categorized as favorable (mRS0-1) or unfavorable (mRS2-6).

Findings: Favorable outcomes (mRS0-1) were obtained in 13 of 17 patients. Post-treatment recurrence occurred in 1 patient with selective coiling in 15 months follow-up, and the patient received stent-assisted coiling. The only patients with stent-assisted coiling developed posterior inferior cerebellar artery occlusion during follow- up. Aneurysm located in distal segment usually presented with intraventricular hemorrhage $(\mathrm{P}=0.015)$. Hypertension, coexisting hydrocephalus and time to operation (latter than 2 weeks) were associated with unfavorable outcome.

Conclusions: Endovascular treatment of isolated dissecting aneurysm of posterior inferior cerebellar artery had excellent clinical outcomes, hypertension, coexisting hydrocephalus and time to operation (latter than 2 weeks) were associated with unfavorable outcome. Long-term follow-ups are necessary to provide stronger conclusions.

Key words: Aneurysm; Dissecting; Posterior inferior cerebellar artery; Selective coiling; Parent artery occlusion; Outcome 
${ }^{*}$ Corresponding Author: Director and Professor Chuan-Zhi Duan:

Address: Department of Neurosurgery/Neurosurgery Institute/Key Laboratory on Brain Function Repair and Regeneration of Guangdong, Southern Medical University, Zhujiang Hospital, 253\# industry road, 510282, Guangzhou, Guangdong, China;

Tel: +86-013539962233; Fax: +86-020-61643269;

E-mail: address: doctorduanzj@163.com. 
Goals: Isolated dissecting aneurysms of the posterior inferior cerebellar artery are rare lesions which carry high risk of rebleeding and mortality. However, the existing literature concerning predictors of outcome after endovascular treatment is limited and controversial. Our present study retrospectively reviewed and analyzed the clinical outcome of endovascular treatment ruptured PICA dissecting aneurysms and explored the predictors of outcome.

Materials and methods: We retrospectively reviewed 17 consecutive patients with ruptured posterior inferior cerebellar artery dissecting aneurysms that underwent endovascular treatment from January 2003 to January 2014. 9 patients underwent selective coiling while 7 patients underwent parent artery occlusion; one patient underwent stent-assisted coiling. Follow-up outcomes were evaluated using modified Rankin Scale. The clinical outcomes of patients were categorized as favorable (mRS0-1) or unfavorable (mRS2-6).

Findings: Favorable outcomes (mRS0-1) were obtained in 13 of 17 patients. Post-treatment recurrence occurred in 1 patient with selective coiling in 15 months follow-up, and the patient received stent-assisted coiling. The only patients with stent-assisted coiling developed posterior inferior cerebellar artery occlusion during follow- up. Aneurysm located in distal segment usually presented with intraventricular hemorrhage $(\mathrm{P}=0.015)$. Hypertension, coexisting hydrocephalus and time to operation (latter than 2 weeks) were associated with unfavorable outcome.

Conclusions: Endovascular treatment of isolated dissecting aneurysm of posterior inferior cerebellar artery had excellent clinical outcomes, hypertension, coexisting 
hydrocephalus and time to operation (latter than 2 weeks) were associated with unfavorable outcome. Long-term follow-ups are necessary to provide stronger conclusions.

Key words: Aneurysm; Dissecting; Posterior inferior cerebellar artery; Selective coiling; Parent artery occlusion; Outcome

\section{Introduction}

Posterior inferior cerebellar artery (PICA) aneurysms account for $0.5-3 \%$ of all intracranial aneurysms [5, 23]. According to special anatomy and etiology, they are classified into saccular and dissecting types. Saccular lesions usually arise at bifurcation or vessel turns which caused by haemodynamic stress. Dissecting aneurysms of the PICA are rare lesions which account for $0.5-0.7 \%$ of all intracranial aneurysms [15]. Some study reported that dissecting etiology accounted for $0-80 \%$ of peripheral aneurysm of PICA $[12,16]$. Owing to their lower incidence and uncertain pathogenesis, the suitable treatment has under debate. Surgical treatment is associated with high risk of transient or permanent neurologic complications. Endovascular treatment has become an alternative to surgery due to lower cranial deficit and achieves better clinical outcomes [7]. However, the existing literature concerning predictors of outcome after endovascular treatment is limited and controversial $[4,22]$. Our present study retrospectively reviewed and analyzed consecutive series of 17 patients with ruptured PICA dissecting aneurysms submitted to endovascular treatment and explored the predictors of outcome.

\section{Materials and Methods}


The Ethics committee of Southern Medical University affiliated Zhujiang Hospital approved this retrospective study. Written informed consent was given by participants for their clinical records to be used in this study.

\section{Patients}

We conducted a retrospective review of 17 consecutive patients with ruptured PICA dissecting aneurysms who underwent endovascular treatment between January 2003 and December 2014. The distribution of subarachnoid hemorrhage (SAH), intraventricular hemorrhage (IVH) and the presence of hydrocephalus were confirmed by CT scans. The diagnosis of dissecting aneurysm was based on clinical manifestations and radiographic findings, including CTA, MRA and conventional angiography. At least two of the following features should be confirmed: intramural hematoma, intimal flap, double-lumen sign and dilation with proximal or distal stenosis, contrast media retention. All patients were evaluated by two neurosurgeons and two neuroradiologists. The type of therapy was not randomized; it was determined by the neurosurgeon's discretion. Aneurysms located at the vertebral artery -PICA junction or vertebral artery dissecting aneurysms extending to the PICA were excluded. Aneurysm involved brain arteriovenous malformation was also excluded in our study. The location of the aneurysm was recorded according to the classification described by Lister et al [14], including anterior medullary, lateral medullary, tonsillomedullary, telovelotonsillar and cortical segments. The clinical outcomes of patients were categorized as favorable (mRS0-1) or unfavorable (mRS2-6). According to the time to operation, they can be classified into acute phase 
(less than 2 weeks) and chronic phase (latter than 2 weeks).

\section{Endovascular procedures}

All patients underwent endovascular treatment under general anesthesia. After a 6-French introducer sheath was placed in the right femoral artery, a 5-French guiding catheter was advanced into the vertebral or subclavian artery, proximal to the lesion. Full systemic heparinization was then performed, by administering a 5000 IU bolus, followed by a continuous infusion of $1000 \mathrm{IU} / \mathrm{h}$. throughout the procedure, the activated clotting time was maintained two to three times above baseline. After an optimal angiographic projection was achieved, a microcatheter was directed into the lesion through the guidewire. Coils were placed through the microcatheter into the aneurysm and detached under fluoroscopy. Parent artery occlusion (PVO) was also performed with coils, but balloon text occlusion was not performed in patients treated with parent artery occlusion. However, the capability of the patient to tolerate PICA occlusion was assessed in diagnostic angiogram based on the presence and size of potentials collateral vessels such as contralateral PICA, ipsilateral anterior inferior cerebellar artery and superior cerebellar artery. The stent was deployed to cover the whole dissecting segment. Several types of coils were used (GDC or Matrix, Boston Scientific Corporation, Natick, MA; EDC, eV3 Neurovascular, Irvine, CA), and consisted of the Enterprise stent (Cordis Corporation, Miami Lake, FL, USA). After the procedure, patients were continuously monitored for $24 \mathrm{~h}$ in our neurosurgery intensive care unit. The patient who underwent stent-assisted coiling received clopidogrel and aspirin for 3 months; after 3 months, aspirin alone was administered 
for 1 year.

\section{Choice of treatment}

The embolization method was selected on the basis of locations and imagining basis. Selective coiling of the aneurysm with parent artery preservation was preferred :(1) proximal location (2)absence of or dysplasia of ipsilateral anterior inferior cerebellar artery or superior cerebellar artery (3) large PICA diameter. On the other hand, patients with distal aneurysms of PICA and potential sufficient collateral supply were submitted to parent artery occlusion.

\section{Data collection}

Patient demographics, pretreatment clinical status, coexisting diseases, treatment methods, post-treatment recurrence, obliterate grade, outcomes of prognosis were recorded. The characteristic of the aneurysm include its location and size was also analyzed.

\section{Clinical assessment and follow-up}

Pretreatment clinical status was according to the classification of Hunt and Hess. Clinical outcomes after procedure were evaluated using the modified Rankin Scale (mRS) score, which was measured by neurologic examination or a structured telephone interview. Each patient's clinical status at the follow-up visit was defined as the final outcome. Our routine imaging follow-up conventional angiography or MR angiography performed between 6 months and 12 months and 18 months following treatment. If no evidence of recurrence aneurysm was detected, further follow-up was not required. The percentage of obliteration was based on angiographic results at the 
final follow-up visit. Complete obliteration was defined as the aneurysmal sac was completely obliterated; partial obliteration was defined as a small residual aneurysm in the neck or fundus; and recurrence was defined as an increase in size in the contrast medium- filled portion of the dissecting aneurysm compared with a control angiogram taken immediately after treatment.

\section{Statistical Analysis}

Continuous variables were compared using unpaired t test or a Mann-Whitney $\mathrm{U}$ test, as appropriate. Categorical variables were compared using the Pearson's chi-squared or Fisher test, as appropriate. A p-value of less than 0.05 was considered statistically significant. Statistical analysis was performed using SPSS statistical software (SPSS13.0 Chicago, IL, USA).

\section{Result}

\section{Patients and aneurysm}

There were 8 men and 9 women (mean age 53.8 years, age ranged 43 to 79 years). 9 patients underwent selective coiling, while 8 patients underwent occlusion aneurysm and parent artery, only one patient received stent-assisted coiling. All the patients presented with SAH. SAH and intraventricular hemorrhage were evident in 9 patients; SAH and hydrocephalus were present on 5 patients. Dissecting aneurysms with other parts of aneurysms were in 4 patients. Hunt-Hess grading at admission was as follows: grade 1,2 patients, grade 2, 9 patients, grade 3, 4 patients, grade4, 2 patients. The location of the aneurysm was anterior medullary in 1, lateral medullary in 4 , tonsillomedullary in 7 , telovelotonsillar in 5 .The maximal diameter of the 
aneurysms ranged from $3 \mathrm{~mm}$ to $15 \mathrm{~mm}$ (mean ,5.2 $\mathrm{mm}$ ). The demographic and aneurysm characteristic were summarized in (Table 1).

\section{Angiographic follow-up}

Angiographic follow-up of the patients was available for a mean of 10.7 months, (3 ranges to 24 months); Post-treatment recurrence occurred in 1 patient with selective coiling during 15 month follow-up, and the patient received stent-assisted coiling(figure 1). Bleeding occurred in 1 patient in operation and received parent artery occlusion. The only patient with stent-assisted coiling developed PICA occlusion during 1 month follow- up, the territory of artery distal to aneurysm was filling by bilateral anterior inferior cerebellar artery. Recurrence or infarction was not discovered in other patients.

\section{Clinical follow-up}

Clinical follow-up of the patients was available for a mean of 13.5 months, (3 ranges to 30 months). Favorable outcomes (mRS 0-1) were obtained in 13 of 17 patients. The patient who diagnosed as aneurysm recurrence received stent-assisted coiling had a good clinical outcome (mRS0). The only patients with stent-assisted coiling developed PICA occlusion without any cerebellar ischemia symptoms. 4 of 5 patients with hydrocephalus who received ventriculo-peritoneal shunt or lumboperitoneal shunt had a bad prognosis (mRS2-6). There were no neurologic complications such as cerebellar or brain stem ischemia, infraction and bleeding in patients underwent parent artery occlusion (figure 2).

\section{Comparability of the study groups}


Aneurysm located in distal segment (tonsillomedullary, telovelotonsillar and cortical segments) presented with intraventricular hemorrhage $(\mathrm{P}=0.015)$ (Table 2). There was no statistically significant difference between outcomes groups with regards to age, gender, size, or site of the aneurysms (Table 2). Hypertension, coexisting hydrocephalus and time to operation (latter than 2 weeks) were associated with unfavorable outcome (Table 3).

\section{Discussion}

Posterior inferior cerebellar artery dissecting aneurysms are a well known cause of stroke and subarachnoid hemorrhage. Owing to the low incidence, the pathogenesis of aneurysm is still unknown, but is thought to be hypertension, fragilities of the embryological vascular development or degenerative changes [20]. Hemodynamic stress has been suspected to be the first etiological factors which contribute to elastic lamina injury and subsequent aneurysm formation [8].

Our study indicated a predominance of women $(52.9 \%$ vs $47.1 \%)$, which is consistent with those of previous studies [1]. There was also a left dominance in our patients; the result was in accordance with other reports [22]. The possible reason is that the left vertebral artery was usually larger than the right one, which suffers more hemodynamic stress. Some studies demonstrated the distal PICA aneurysms most located at origin or in the first anterior medullary segment of the PICA. In our cases, the most common site of the aneurysm was at the tonsillomedullary and telovelotonsillar segment; maybe these segments suffer grater hemodynamic stress due to the vessel bends. 
The PICA supplies blood to the caudal medulla, cerebellar tonsils, and inferior portion of the cerebellar hemisphere, vermis, and choroid plexus of the fourth ventricle. Kanou et al. reported that dissecting aneurysms of the proximal PICA tended to cause infarctions while peripheral dissections tended to lead to SAH [9]. Our study demonstrated that aneurysms located in distal segment of PICA prone to present intraventricular hemorrhage. $(\mathrm{P}=0.015)$, and there was no significance between groups in age, gender, size and hypertension.

The natural history of dissecting aneurysm is different from the common saccular or berry aneurysm usually arising at the VA-PICA junction [2]. The most common presentation of the dissecting aneurysm of PICA is hemorrhage, in the acute phase they usually carries a high risk of rebleeding, associated with a high mortality rate[6]. In our study, all the aneurysms were ruptured, early interventional therapy is essential to prevent rebleeding. However, the suitable management was controversial. Surgical treatment is associated with high neurologic complication related to lower cranial nerve palsies [1]. Endovascular treatment is rapidly gaining popularity and achieves better clinical outcomes [21]. The treatment mainly includes selective coiling with parent artery preservation, parent artery occlusion and stent-assisted coiling.

Parent artery occlusion is thought to the most reliable technique for ruptured dissecting aneurysms of PICA [19]. However, parent artery occlusion of PICA was potentially associated with two types of ischemic events. First, brain stem ischemia owing to obliteration the perforating arteries supplying the brain stem originate the first 2 proximal segment of the PICA (anterior medullary, lateral medullary) and the 
second cerebellar ischemia distal to the occlusion site. Because of the numerous anastomoses of the perforating arteries forming a plexiform network on the medullary, the risk of brain stem ischemia was limited [6]. However, Oran reported one aneurysm located at the anterior medullary segment resulted in brain stem infarction after PVO [18]. Besides, collateral supply from the contralateral PICA or ipsilateral anterior inferior cerebellar artery and superior cerebellar artery is reported to be sufficient to prevent ischemia. Nussbaum et al reported PICA occlusion distal to the telovelotonsillar segment generally did not result in brain stem injury [17]. But Rene reported three patients developed mild cerebellar ischemia despite of the presence of collaterals [24]. In our cases, none of the patients treated with PVO showed cerebral ischemia or any deterioration, we found that aneurysms treated with PVO were all located in the tonsillomedullary or distal segment of PICA.

Since it is impossible to predict on angiography the individual tolerance to occlusion of the PICA, some experts suggested that selective coiling without parent artery occlusion may be effectively decrease the risk of cerebral ischemia [13]. In patients with a larger PICA, sacrifice the vessel may develop severe cerebellar edema. Trivelato compared selective coiling and parent artery occlusion for treatment of isolated PICA dissecting they concluded that parent artery occlusion was significantly associated with higher risk of ischemia, only one patient treated with selective coiling developed aneurysm recurrence[23]. However, the disadvantage of this technique also has the risk of aneurysm recurrence which may predispose the aneurysm to rerupture. Fujimura reported a case of fatal rebleeding after selective embolization of dissecting 
PICA aneurysms [3]. In our study, one recurrence was observed in patients treated with selective coiling during 15 month follow- up. We conclude that the whole dissection may be incompletely closed, the limited retrograde or antegrade filling of the dissected segment provide little impetus for enlargement of the aneurysm. Therefore, a careful follow- up study is recommended to detect recurrence for these aneurysms.

Although endovascular treatment of dissecting aneurysm of PICA has gained better clinical outcomes, a few series have analyzed the factors predicting clinical outcomes; our study aimed to explore the factors affecting the prognosis.

Time of treatment and outcome

The time of treatment is the key element for rebleeding prevention because treatment delays are associated with an increased risk of mortality [10]. The mean delay from initial bleeding to endovascular treatment was 10.2 days, the mean time was in 8 days the favorable outcome group but in the unfavorable group 17.5days, there was statistically significant difference in time of embolization with clinical prognosis between groups $(\mathrm{P}=0.022)$. The unfavorable delay was partly due to the poor clinical condition of the patients with hydrocephalus or intraventricular hemorrhage .On the other hand, limited knowledge concerning the diagnosis and suitable treatment also had prolonged the delay. We concluded that early treatment was essential for better outcomes especially in ruptured dissecting aneurysms of PICA.

Hydrocephalus and outcome 
Our study demonstrated that patients with hydrocephalus were related with bad prognosis $(\mathrm{P}=0.004)$ which was consistent with the previous study [4]. 4 of 5 patients with hydrocephalus who received ventriculo-peritoneal shunt or lumboperitoneal shunt, 3 patients had an unfavorable outcome (mRS2-6). It is necessary to release the bloody cerebrospinal fluid to decrease the incidence of hydrocephalus.

Hypertension and outcome

Dissection usually occurs when there is a tear in the wall leading to intrusion of blood within the layers and formation of an intramural hematoma. One study based on 5 years of data found that spontaneous dissections occurred more frequently in patients with preexisting hypertension [25]. Hemodynamic stress was also thought to the etiological factors which contribute to elastic lamina injury and subsequent aneurysm formation. Our result found that hypertension was associated with unfavorable outcome $(\mathrm{P}=0.022)$, we concluded that hypertension may be related with hemodynamic stress which contributed to aneurysm rupture and affected the prognosis.

In our study, no significant differences in outcome related to treatment modalities (selective coiling or parent artery occlusion). In the initial treatment, due to the small tortuous of PICA, there was only one aneurysm located at the lateral medullary segment received stent-assisted coiling. After the procedure, angiogram showed that there was a filling defect in the VA-PICA junction. Although taking anticoagulant and antiplatelet therapy, PICA occlusion occurred during 1 month follow -up, the territory of artery distal to aneurysm was filling by bilateral anterior inferior cerebellar artery 
and no cerebral ischemia occurred. Another patient treated with selective coiling developed recurrence in 15 months after the procedure and received stent-assisted coiling; there was no recurrence during follow- up. Due to the limited cases, we could not conclude stent-assisted coiling was associated with clinical outcome; large cases were needed to evaluate the effect of this modality.

There were several limitations in our study. First, because of its retrospective nature, inherent bias could not be avoided. Second, the limited period of analysis may not be long enough to draw definitive conclusions. Third, because of the short-term follow-up period, some complications may have been underestimated.

\section{Conclusions}

Endovascular treatment of isolated dissecting aneurysm of PICA was safe and effective. Hypertension, coexisting hydrocephalus and time to operation (latter than 2 weeks) were associated with unfavorable outcome. Long-term follow-ups were necessary to provide the stronger conclusions.

\section{References}

1. Anegawa S, Hayashi T, Torigoe R, Nakagawa S, Furukawa Y, Tomokiyo M (2001) [Aneurysms of the distal posterior inferior cerebellar artery--analysis of 14 aneurysms in 13 cases]. No Shinkei Geka 29:121-129

2. Cellerini M, Mangiafico S, Ammannati F, Ambrosanio G, Muto M, Galasso L, Mennonna P (2008) Ruptured, dissecting posterior inferior cerebellar artery aneurysms: endovascular treatment without parent vessel occlusion. Neuroradiology 50:315-320

3. Fujimura M, Nishijima M, Midorikawa H, Umezawa K, Hayashi T, Kaimori M (2003) Fatal rupture following intra-aneurysmal embolization for the distal posterior inferior cerebellar artery aneurysm with parent artery preservation. Clin Neurol Neurosurg 105:117-120

4. Horiuchi T, Tanaka Y, Hongo K, Nitta J, Kusano Y, Kobayashi S (2003) Characteristics of distal posteroinferior cerebellar artery aneurysms. Neurosurgery 53:589-595, 595-596

5. Hudgins RJ, Day AL, Quisling RG, Rhoton AJ, Sypert GW, Garcia-Bengochea F (1983) Aneurysms of the posterior inferior cerebellar artery. A clinical and anatomical analysis. J Neurosurg 


\section{8:381-387}

6. Ioannidis I, Nasis N, Andreou A (2012) Endovascular treatment of ruptured dissecting posterior inferior cerebellar artery aneurysms. Interv Neuroradiol 18:442-448

7. Ishihara H, Tateshima S, Jahan R, Gonzalez N, Duckwiler G, Vinuela F (2013) Endovascular treatment of ruptured dissecting aneurysms of the posterior inferior cerebellar artery. J Neurointerv Surg 5:557-561

8. Isokangas JM, Siniluoto T, Tikkakoski T, Kumpulainen T (2008) Endovascular treatment of peripheral aneurysms of the posterior inferior cerebellar artery. AJNR Am J Neuroradiol 29:1783-1788

9. Kanou Y, Arita K, Kurisu K, Ikawa F, Eguchi K, Monden S, Watanabe K (2000) Dissecting aneurysm of the peripheral posterior inferior cerebellar artery. Acta Neurochir (Wien) 142:1151-1156

10. Lee JM, Kim TS, Joo SP, Yoon W, Choi HY (2010) Endovascular treatment of ruptured dissecting vertebral artery aneurysms--long-term follow-up results, benefits of early embolization, and predictors of outcome. Acta Neurochir (Wien) 152:1455-1465

11. Lee KS, Gower DJ, Branch CJ, Kelly DJ, McWhorter JM, Bell WO (1989) Surgical repair of aneurysms of the posterior inferior cerebellar artery--a clinical series. Surg Neurol 31:85-91

12. Lewis SB, Chang DJ, Peace DA, Lafrentz PJ, Day AL (2002) Distal posterior inferior cerebellar artery aneurysms: clinical features and management. J Neurosurg 97:756-766

13. Lim SM, Choi IS, Hum BA, David CA (2010) Dissecting aneurysms of the distal segment of the posterior inferior cerebellar arteries: clinical presentation and management. AJNR Am J Neuroradiol $31: 1118-1122$

14. Lister JR, Rhoton AJ, Matsushima T, Peace DA (1982) Microsurgical anatomy of the posterior inferior cerebellar artery. Neurosurgery 10:170-199

15. Maimon S, Saraf-Lavi E, Rappaport ZH, Bachar G (2006) Endovascular treatment of isolated dissecting aneurysm of the posterior inferior cerebellar artery. AJNR Am J Neuroradiol 27:527-532

16. Mitsos AP, Corkill RA, Lalloo S, Kuker W, Byrne JV (2008) Idiopathic aneurysms of distal cerebellar arteries: endovascular treatment after rupture. Neuroradiology 50:161-170

17. Nussbaum ES, Madison MT, Myers ME, Goddard J, Janjua T (2008) Dissecting aneurysms of the posterior inferior cerebellar artery: retrospective evaluation of management and extended follow-up review in 6 patients. J Neurosurg 109:23-27

18. Oran I, Cinar C, Yagci B, Tarhan S, Kiroglu Y, Serter S (2009) Ruptured dissecting aneurysms arising from non-vertebral arteries of the posterior circulation: endovascular treatment perspective. Diagn Interv Radiol 15:159-165

19. Peluso JP, van Rooij WJ, Sluzewski M, Beute GN, Majoie CB (2008) Posterior inferior cerebellar artery aneurysms: incidence, clinical presentation, and outcome of endovascular treatment. AJNR Am J Neuroradiol 29:86-90

20. Ro A, Kageyama N, Abe N, Takatsu A, Fukunaga T (2009) Intracranial vertebral artery dissection resulting in fatal subarachnoid hemorrhage: clinical and histopathological investigations from a medicolegal perspective. J Neurosurg 110:948-954

21. Shin HS, Lee SH, Koh JS (2014) Endovascular treatment of ruptured distal posterior inferior cerebellar artery aneurysm. Report of two exemplary cases and retrospective analysis of 11 cases. J Neurol Surg A Cent Eur Neurosurg 75:343-349

22. Tokimura H, Yamahata H, Kamezawa T, Tajitsu K, Nagayama T, Sugata S, Takiguchi K,

Taniguchi A, Niiro M, Hirahara K, Takasaki K, Oyoshi T, Arita K (2011) Clinical presentation and treatment of distal posterior inferior cerebellar artery aneurysms. Neurosurg Rev 34:57-67 
23. Trivelato FP, Salles RM, Castro GD, Manzato LB, Santoro AJ, Ulhoa AC (2014) Endovascular treatment of isolated posterior inferior cerebellar artery dissecting aneurysms: parent artery occlusion or selective coiling? Clin Neuroradiol 24:255-261

24. van den Berg R, Doorschodt TC, Sprengers ME, Vandertop WP (2014) Treatment of dissecting aneurysms of the PICA: Anatomical considerations and clinical outcome. J Neuroradiol

25. Yaghi S, Maalouf N, Keyrouz SG (2012) Cervical artery dissection: risk factors, treatment, and outcome; a 5-year experience from a tertiary care center. Int J Neurosci 122:40-44

\section{Figure legends}

Figure 1. 48-year-old male presenting 9 days after SAH from PICA dissecting aneurysms

A: The brain CT shows SAH after admission B: The left angiogram shows a $3 \times 4 \mathrm{~mm}$ left PICA dissecting aneurysm C: DSA shows total occlusion of the aneurysm with selective coiling D: The angiogram shows regrowth of the aneurysm during 15-month follow up. E : Additional stent was placed to occlude the aneurysm F: The aneurysm stays stable without recurrence during 24 month follow- up

Figure 2 .48-year-old female presenting SAH from PICA dissecting aneurysms

A: The brain CT shows fourth intraventricular hemorrhage after admission B: Three dimensional angiogram shows right the PICA dissecting aneurysm C: The right angiogram shows a $3 \times 3 \mathrm{~mm}$ right PICA dissecting aneurysm D: DSA shows total occlusion of the aneurysm and parent artery E: The aneurysm stays stable without recurrence during 6-month follow- up 
Table 1.

Summary of data in patients with dissecting aneurysms of the posterior inferior cerebellar artery

\begin{tabular}{|c|c|c|c|c|c|c|c|c|c|c|c|c|}
\hline Case & Sex & Age & Hypertension & Hunt-Hess & $\operatorname{Size}(\mathrm{mm})$ & Side & Location & Hydrocephalus & $\begin{array}{l}\text { Coexisting } \\
\text { aneurysms }\end{array}$ & $\begin{array}{l}\text { Intraventricular } \\
\text { hemorrhage }\end{array}$ & $\begin{array}{l}\text { Time to } \\
\text { embolization(d) }\end{array}$ & $\begin{array}{l}\text { Treatment } \\
\text { modality }\end{array}$ \\
\hline 1 & $\mathrm{M}$ & 48 & No & II & 4 & $\mathrm{~L}$ & 1 & No & Yes & No & $<14$ & simlpe coil \\
\hline 2 & $\mathrm{~F}$ & 43 & No & III & 6 & $\mathrm{R}$ & 4 & No & No & Yes & $<14$ & simple coli \\
\hline 3 & M & 68 & Yes & II & 5 & $\mathrm{R}$ & 3 & Yes & No & No & $>14$ & stent \\
\hline 4 & M & 55 & No & I & 15 & $\mathrm{R}$ & 3 & No & No & Yes & $<14$ & PVO \\
\hline 5 & M & 42 & No & III & 6 & $\mathrm{~L}$ & 3 & No & No & Yes & $<14$ & simlpe coil \\
\hline 6 & $\mathrm{~F}$ & 45 & No & II & 5 & $\mathrm{~L}$ & 4 & No & No & Yes & $<14$ & PVO \\
\hline 7 & M & 54 & No & II & 4 & $\mathrm{R}$ & 3 & No & No & Yes & $<14$ & PVO \\
\hline 8 & $\mathrm{~F}$ & 79 & No & II & 5 & $\mathrm{~L}$ & 3 & No & No & Yes & $<14$ & simlpe coil \\
\hline 9 & $\mathrm{~F}$ & 44 & Yes & III & 4 & $\mathrm{R}$ & 4 & Yes & Yes & Yes & $<14$ & simlpe coil \\
\hline 10 & $\mathrm{~F}$ & 47 & No & IV & 5 & $\mathrm{~L}$ & 2 & Yes & Yes & No & $>14$ & simlpe coil \\
\hline 11 & M & 67 & No & I & 5 & $\mathrm{~L}$ & 4 & No & Yes & No & $<14$ & PVO \\
\hline 12 & M & 62 & Yes & II & 5 & $\mathrm{~L}$ & 2 & No & No & No & $<14$ & simlpe coil \\
\hline 13 & M & 63 & Yes & IV & 2.5 & $\mathrm{~L}$ & 4 & Yes & No & Yes & $>14$ & PVO \\
\hline 14 & $\mathrm{~F}$ & 46 & No & II & 5 & $\mathrm{R}$ & 2 & No & No & No & $<14$ & simlpe coil \\
\hline 15 & $\mathrm{~F}$ & 41 & No & II & 4 & $\mathrm{~L}$ & 2 & No & No & No & $<14$ & simlpe coil \\
\hline 16 & $\mathrm{~F}$ & 48 & No & II & 3 & $\mathrm{R}$ & 3 & Yes & No & Yes & $>14$ & PVO \\
\hline 17 & $\mathrm{~F}$ & 58 & No & III & 4 & $\mathrm{~L}$ & 3 & No & No & No & $<14$ & PVO \\
\hline
\end{tabular}

PVO: parent artery occlusion

The location of distal posterior inferior cerebellar artery aneurysms were divided into five segments: (1) anterior medullary,

(2) lateral medullary, (3)tonsillomedullary, (4)telovelotonsillar and(5) cortical segments 
Table 2 Summary of data in patients with intraventricular hemorrhage

\begin{tabular}{llll}
\hline Variable & \multicolumn{2}{c}{ Intraventricular hemorrhage } & P value \\
& Yes(n=9) & No(n=8) & $1.00^{*}$ \\
\hline Gender & 4 & 4 & \\
Man & 5 & 4 & $0.758^{\#}$ \\
Women & $52.9 \pm 12.2$ & $54.6 \pm 10.4$ & $0.540^{\S}$ \\
Age $(\mathrm{yr}$, mean \pm SD) & $5.7 \pm 3.7$ & $4.5 \pm 0.5$ & $0.433^{*}$ \\
Size(mean \pm SD) & 5.7 & & \\
Location & & 6 & $0.479^{*}$ \\
Left & 4 & 2 & \\
Right & 5 & & \\
Hypertension & & 3 & $0.015^{\S}$ \\
Yes & 1 & 5 & \\
No & 8 & & \\
Segment & & 1 & \\
1 & 0 & 4 & \\
2 & 0 & 2 & \\
3 & 5 & 1 & \\
4 & 4 & & \\
\hline
\end{tabular}

$*: \chi^{2} \quad$ \#:T-test $\S:$ Mann-Whitney 
Table 3 Predictors of outcome of patients with ruptured posterior inferior cerebellar artery dissecting aneurysms

\begin{tabular}{|c|c|c|c|}
\hline Variable & $\begin{array}{l}\text { Favorable outcome } \\
(\mathrm{n}=13)\end{array}$ & $\begin{array}{l}\text { Unfavorable outcome } \\
(\mathrm{n}=4)\end{array}$ & $P$ value \\
\hline Gender & & & $1.00^{*}$ \\
\hline Man & 6 & 2 & \\
\hline Women & 7 & 2 & \\
\hline $\operatorname{Age}(\mathrm{yr}, \mathrm{mean} \pm \mathrm{SD})$ & $53.2 \pm 11.2$ & $55.5 \pm 11.8$ & $0.724^{\#}$ \\
\hline $\operatorname{Size}($ mean \pm SD $)$ & $5.5 \pm 3.0$ & $4.1 \pm 1.2$ & $0.400^{\S}$ \\
\hline Location & & & $1.00^{*}$ \\
\hline Left & 8 & 2 & \\
\hline Right & 5 & 2 & \\
\hline Hypertension & & & $0.022^{+}$ \\
\hline Yes & 1 & 3 & \\
\hline No & 12 & 1 & \\
\hline Coexisting aneurysms & & & $0.219^{+}$ \\
\hline Yes & 2 & 2 & \\
\hline No & 11 & 2 & \\
\hline Hydrocephalus & & & $0.004^{*}$ \\
\hline Yes & 1 & 4 & \\
\hline No & 12 & 0 & \\
\hline Intraventricular hemorrhage & & & $1.00^{*}$ \\
\hline Yes & 7 & 2 & \\
\hline No & 6 & 2 & \\
\hline Time to embolization & & & $0.022^{+}$ \\
\hline$<14$ days & 12 & 1 & \\
\hline$>14$ days & 1 & 3 & \\
\hline
\end{tabular}


Treatment modality

Selective coiling

Parent artery occlusion

Stent-assisted coiling

Hunt-Hess

1

2

3-4

*: $\chi^{2} \quad$ \#: T -test $\S:$ Mann-Whitney +: Fisher's exact tes
$0.609^{\S}$

$0.068^{\S}$

20

$8-1$

$3 \quad 3$

2

1 
Figure 1
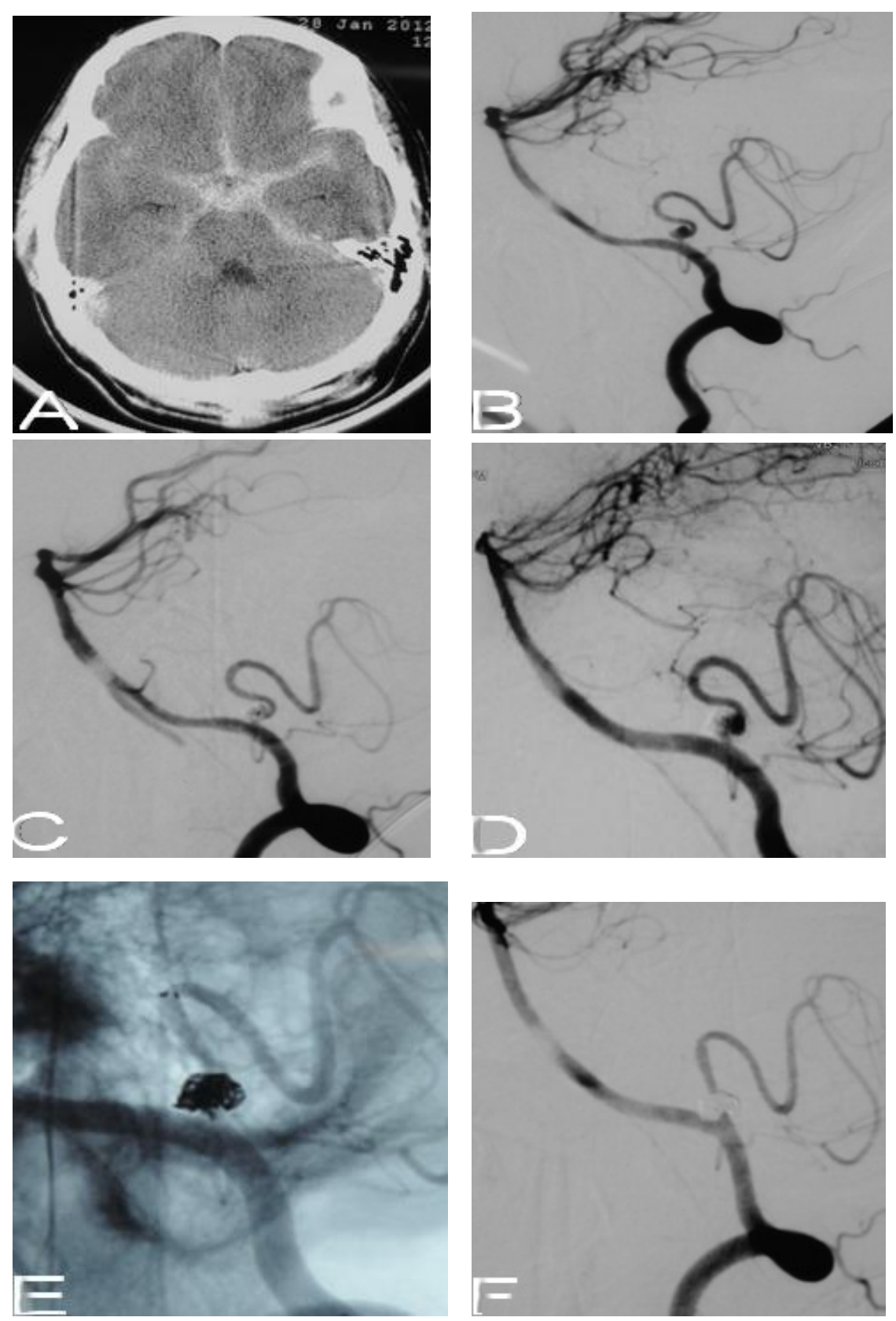
Figure 2
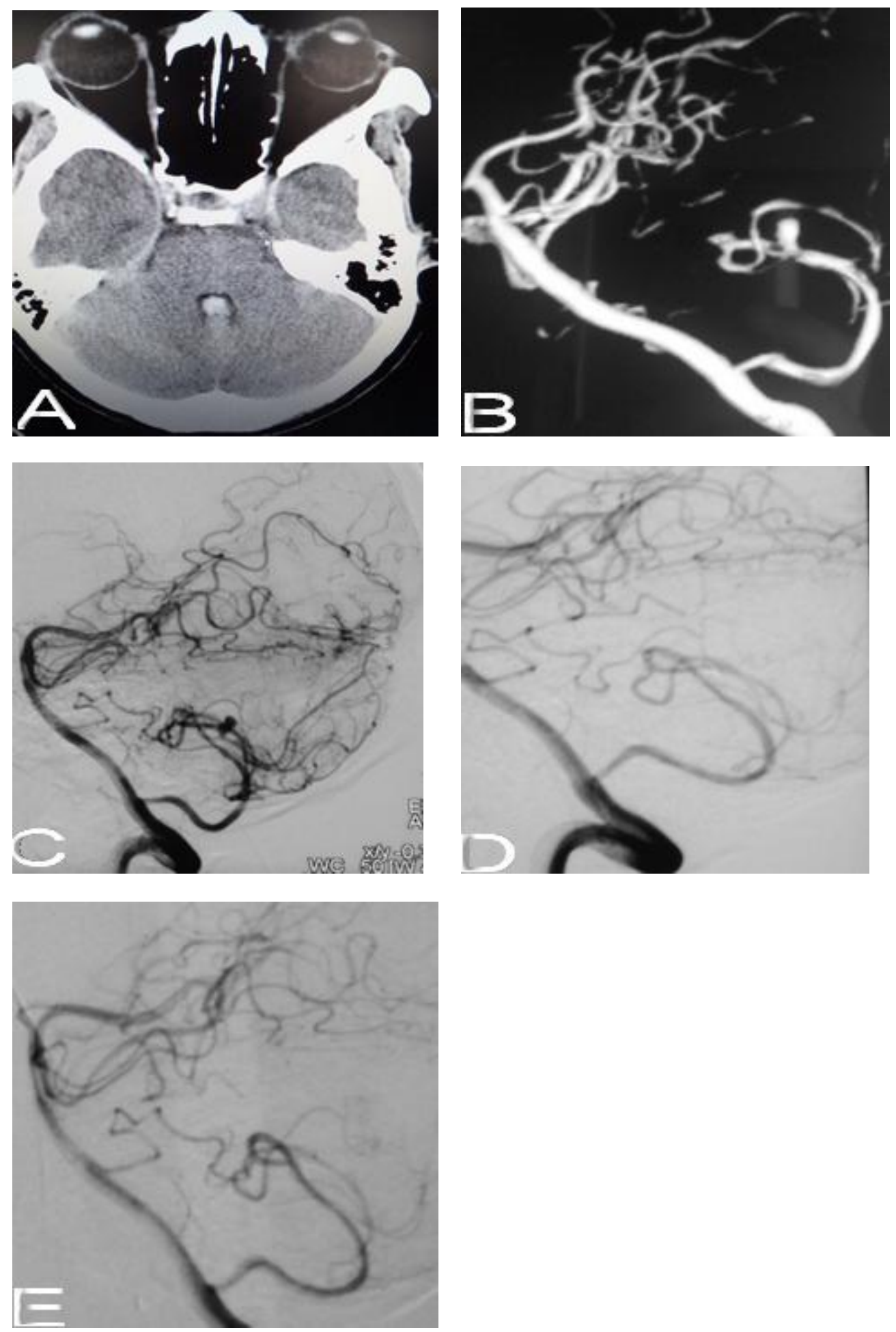